\title{
Kartleggingsverktøy i skulehelsetenesta har både fordelar og ulemper
}

Verktøya kan sikre at helsesjukepleiarane tek opp sentrale tema hos alle elevar. Samstundes kan det bli vanskelegare å leggje til rette for myndiggjering og brukarmedverknad.

\section{Tove Linn Øren}

Helsesjukepleiar

Helsestasjons- og skulehelsetenesta, Barne- og familetenesta i Arna og Åsane, Bergen kommune

Olina Kollbotn

Førsteamanuensis

Institutt for helse- og omsorgsvitskap, Høgskulen på Vestlandet

Astrid Synnøve Litland

Helsesykepleier og førstelektor

Skolehelsetjenesten, Bergen kommune og Fakultet for helse- og sosialvitskap, Høgskulen på Vestlandet

Kvalitativ forskning

Helsesjukepleiar
Elektronisk journalsystem

Kvalitet i helsetjenesta

\section{Hovedbudskap}


Helsesjukepleiar sin bruk av standardiserte kartleggingsverktøy kan både fremje og hemme kvaliteten på tenesta. Verktøyet kan gjere det vanskeleg for helsesjukepleiarar å leggje til rette for myndiggjering (empowerment) og brukarmedverknad, samstundes som det sikrar at sentrale tema blir tatt opp hos alle elevar. Det er nødvendig med opplæring, og helsesjukepleiarane bør delta i revidering og utvikling av kartleggingsverkt øya.

Rolla til helsesjukepleiaren har gradvis endra karakter frå kontrollfunksjon med problemorientering til rolla som rettleiar og støttespelar for barn, unge og familien deira (1).

Det helsefremjande aspektet i skulehelsetenesta er sentralt, og det blir lagt vekt på tiltak som kan bidra til å styrkje ressursane og trua på eigen kompetanse hos barn, unge og familien $(2,3)$.

Kartlegging av helsetilstand er ei viktig oppgåve i folkehelsearbeidet (4), og regjeringa har store forventningar til systematiske kartleggingsarbeid i kommunane $(5,6)$.

Det har vore ein aukande bruk av standardiserte kartleggingsverkt $\varnothing y$ i skulehelsetenesta, samstundes som den elektroniske journalen skal vere eit system for oppfølging av den enkelte (7).

\section{Helsesamtalen er eit viktig verktøy}

I dei nasjonalfaglege retningslinjene (3) er helsesamtalen framheva som eit viktig verktøy for å fremje helse ved å gi eit individuelt tilpassa tilbod til kvar enkelt elev og foreldra hans eller hennar.

Samtalen bør handle om dialog og brukarmedverknad. I det helsefremjande arbeidet er myndiggjering (empowerment) sentralt, og brukarmedverknad er avgjerande i denne tilnærminga (8).

I 2010 innførte Bergen kommune journalsystemet HsPro (journalsystem for helsestasjoner) med tilleggsmodulen Helseprofil o-20 år (sjå faktaboks), eit kartleggingsverktøy som blir brukt ved helseunders $\varnothing$ kingar ved skulestart, på 3 . trinn, på 8. trinn og på vidaregåande trinn 1, i samtalar med nye elevar og i samtalar med elevar med høgt fråvær.

Helseundersøkingane har gradvis blitt utvida ved at det har blitt lagt til nye spørsmål. Helseunders $\varnothing$ kinga i 3. klasse er frå hausten 2019 fjerna, men var ei av oppgåvene til helsesjukepleiaren på det tidspunktet studien blei utført. 
Helseprofil o-2o blir sett på som ei nyvinning i nasjonal samanheng (9), og det er stadig fleire kommunar som tek i bruk HsPro og tilleggsmodulen Helseprofil o-20.

\section{Helseprofil 0-20 år}

Helseprofil o-20 er ei helseunders $\varnothing$ king som er blitt ein fast del av

- rutinekontrollane for barn og ungdom i helsestasjons- og skulehelsetenesta i Bergen kommune.

- Helseprofil o-2o er eit skjema for strukturert registrering av helseinformasjon i journalsystemet HsPro. Dette er utvikla i Bergen.

- Opplysningane er samla systematisk og strukturert i elektroniske pasientjournalar. Informasjonen gir oversikt over helsetilstanden til barn og unge.

Kjelde: Bentzen A. Fikk pris for unikt helseprosjekt (9)

Ifølgje Golsäter og medarbeidarar (10) kan systematiske helse- og livsstilsverktøy vere nyttige for å gje samtalen struktur og identifisere individuelle behov, men verktøyet kan hemme dialogen om det blir brukt rigid.

Elevane har behov for bli møtte på ein anerkjennande måte der helsesjukepleiaren oppriktig bryr seg og er til stades for ungdommane (11). Ein vellukka helsesamtale kan resultere i sunne refleksjonar og endringar (12).

\section{Kartleggingsverktøy kan generalisere}

Sleveland (13) fann at kartleggingsverktøy utfordra målet til helsesjukepleiarane om å møte brukarane på ein individuell og heilskapleg tilnærmingsmåte, og kunne føre til at dei ikkje stolte på eigen kunnskap og eiga vurderingsevne.

Bruk av lite føremålstenlege elektroniske helsejournalar fører til at helsearbeidarar kontinuerleg må tilpasse journalen ut frå behova til brukarane. Det er derfor viktig at helsearbeidarar som er tett på brukarane, deltek i utvikling og forbetring av dei elektroniske helsejournalane (14).

Ifølgje Nilsen og medarbeidarar (15) påverka karteggingsverktøyet helseunders $\varnothing$ kinga. Helsesjukepleiarane handterte dette ved ulike tilpassingsstrategiar som kan verke inn på kor gyldig kartleggingsverktøyet er. Det blei konkludert med at vidareutvikling og ytterlegare evaluering av dette verktøyet er naudsynt, slik vi har gjort i denne studien. 


\section{Føremål med studien}

Føremålet med studien (16) var å få kunnskap om kva erfaringar helsesjukepleiarar har gjort seg med å bruke det standardiserte kartleggingsverkt øyet for målretta helseunders $\varnothing$ kingar i Helseprofil o-20, i samtalar med elevar og foreldre i skulehelsetenesta.

\section{Metode}

Vi valde kvalitativ tilnærming med intervju som datainnsamlingsmetode fordi det er ein eigna måte for å studere og få kunnskap om erfaringar til menneske, og oppnå ei forståing av sosiale fenomen (17). Studien er inspirert av eit fenomenologisk/hermeneutisk vitskapssyn med vekt på å få fram opplevinga og fortolkinga til informanten.

Teksten blei analysert etter inspirasjon av systematisk tekstkondensering (18). Vi gjekk deretter vidare med temasentrert analyse. Grunnlaget for temasentrert analyse var at vi hadde informasjon frå alle deltakarane om dei same temaa. Ifølgje Thagaard (17) er temabaserte tilnærmingar basert på klassifisering av data, slik tilfellet er i denne studien (tabell 1).

Tabell 1. Hovedtema og undertema

\begin{tabular}{|c|c|c|c|}
\hline Trinn 1. Foreløpige tema & Trinn 2. Koding & Trinn 3. Undergrupper & Trinn 4. Tema \\
\hline $\begin{array}{ll}1 & \begin{array}{l}\text { Kartleggingsverkt } \varnothing \text { y gjev } \\
\text { disposisjon for samtalen }\end{array} \\
2 & \begin{array}{l}\text { Inngangsport til å stille } \\
\text { vanskelege spørsmål }\end{array} \\
3 & \text { Tidsbruk } \\
4 & \text { Kartlegging } \\
5 & \text { Opplæring }\end{array}$ & $\begin{array}{l}\text { Standardiserte } \\
\text { konsultasjonar } \\
\text { Det individuelle } \\
\text { møtet }\end{array}$ & $\begin{array}{l}\text { Kvalitetssikring } \\
\text { av tenesta } \\
\text { Tidsbruk } \\
\text { Ulik oppfatning av } \\
\text { kartleggingsverktøyet } \\
\text { i ulike konsultasjonar } \\
\text { Brukarmedverknad }\end{array}$ & $\begin{array}{l}\text { Kartlegging versus } \\
\text { brukarmedverknad }\end{array}$ \\
\hline $\begin{array}{ll}6 & \text { Møte med elev } \\
7 & \text { Konflikt mellom å fylle ut } \\
\text { spørsmål til punkt og prikke } \\
\text { og eleven sine behov }\end{array}$ & $\begin{array}{l}\text { Fagleg skjønn } \\
\text { og kunnskap }\end{array}$ & $\begin{array}{l}\text { Erfaring med bruk av } \\
\text { kartleggingsverktøyet i } \\
\text { konsultasjonar } \\
\text { Målkonflikt }\end{array}$ & $\begin{array}{l}\text { Kartlegging versus fagleg } \\
\text { kunnskap og skjønn }\end{array}$ \\
\hline 8 Tilbakemelding & Påverknadskraft & $\begin{array}{l}\text { Tilbakemelding } \\
\text { Opplæring }\end{array}$ & $\begin{array}{l}\text { Manglande opplæring og } \\
\text { system for tilbakemelding }\end{array}$ \\
\hline
\end{tabular}

\section{Utval}

Utvalet var ti helsesjukepleiarar frå dei fire byområda i Bergen, då kommunen brukar kartleggingsverktøyet Helseprofil o-2o ved konsultasjonar i skulehelsetenesta. Informantane hadde frå eitt til åtte års erfaring med kartleggingsverktøyet og utgjorde slik eit strategisk utval. 
Informantane fekk skriftleg informasjon om føremålet med studien, og vi innhenta informert samtykke. Studien er godkjend av Norsk senter for forskningsdata (NSD) (prosjektnummer 56512).

\section{Datainnsamling og gjennomføring}

Intervjua blei utførte mellom januar og mars 2018, på arbeidsplassen til helsesjukepleiarane. Førsteforfattaren gjennomførte intervjua, som varte mellom 45 og 65 minutt. Intervjua hadde ein semistrukturert intervjuguide. Det blei brukt lydopptak som deretter blei transkriberte.

\section{Resultat og erfaringar}

Helsesjukepleiarane sine erfaringar med å bruke standardisert kartleggingsverkt $\varnothing \mathrm{y}$ i helseunders $\varnothing$ kingar blei identifisert til følgjande tema: 1) kartlegging versus brukarmedverknad, 2) kartlegging versus fagleg kunnskap og skjønn, 3) manglande opplæring og system for tilbakemelding (sjå tabell 1).

\section{Kartlegging versus brukarmedverknad}

Sjølv om informantane på generelt grunnlag meinte at standardiserte kartleggingsverktøy kan vere ei kvalitetssikring fordi at alle blir kartlagde på den same måten, erfarte helsesjukepleiarane at kartlegginga tok for stor plass i konsultasjonen.

Fleire av helsesjukepleiarane meinte at det var enklare å kome fram til det eleven strevar med, når dei ikkje brukar kartleggingsverktøyet: «Eg trur eg fangar opp mykje meir når det ikkje er den helseunders $\varnothing$ kinga, då er ein meir lydhøyr for det eleven fortel.» (Informant A)

\section{$\equiv$ «Helsesjukepleiarane erfarte at kartlegginga tok for stor plass i konsultasjonen.»}

Fleire av informantane peikte på at det er krevjande å ha for mange konsultasjonar med bruk av kartleggingsverktøyet på rad. Informantane skildrar dette om alle dei ulike helseundersøkingane, på grunn av mengda spørsmål som skal kryssast ut:

«Tredjeklassingar, der klarar eg maks tre på ein dag, for eg blir så lei. Då klarar eg ikkje ha den gode samtalen. Det er ikkje fordi det er slitsamt å snakke med tre elevar på rad, men det er fordi du veit du skal gjennom dei spørsmåla.» (Informant B) 
Fleire helsesjukepleiarar fortel at kartleggingsverktøyet kan vere ein god inngangsport til samtale med elevar. Eit døme er spørsmåla om røyking og rusmiddel: «Då ser dei at dette er ikkje noko eg kjem på fordi eg lurer på dette akkurat med deg, dette er noko vi spør alle om.» (Informant C)

Funna viser også at helsesjukepleiarar kan oppleve ubehag ved å stille enkelte spørsmål i helseundersøkinga. Dei fortel om negative tilbakemeldingar frå foreldre på enkelte spørsmål:

«Eg kan lese på kroppsspråket at no er det rett før dei reiser seg og går. Eg må forklare at dette er statistikk-spørsmål frå Bergen kommune [...] for at det skal bli meir forståeleg kvifor eg spør. Det er rett og slett for å gjere stemninga lettare.» (Informant B)

\section{$\equiv$ «Helsesjukepleiarar kan oppleve ubehag ved å stille enkelte spørsmål i helseundersøkinga.»}

Kartleggingsverktøyet kan gjere det utfordrande å gje eleven brukarmedverknad. Helsesjukepleiarane seier at dei styrer dialogen og legg vekt på at dei skal rekke å bli ferdige med spørsmåla på den tida som er sett av.

Helsesjukepleiarar fortel også at blikkontakten blir annleis ved helseundersøkingar, fordi dei ofte må flytte blikket frå eleven og over på dataskjermen: «Eg styrer det, dei sit på sidelinja og svarar. Det blir litt sånn autoritært.» (Informant C)

Helsesjukepleiarane brukar ord som grilling, tilsyn og forhøyr når dei fortel om korleis dei synest det er å bruke kartleggingsverktøyet: «Så blir vi sånne som skal føre tilsyn, unders $\varnothing$ kje meir, spionere på [...]. Og då kan vi фydeleggje den rolla med at vi skal vere ein som det skal gå an å kome til og ha tillit til.» (Informant D)

\section{Kartlegging versus fagleg kunnskap og skjønn}

Dei erfarne helsesjukepleiarane fortalde at det var viktig med erfaring, fagleg kompetanse og skjønn for å kunne bruke kartleggingsverktøyet på ein god måte:

«Dei nyutdanna bekymrar meg. Dersom dei brukar helseundersøkinga som ho er, blir det ein veldig dårleg samtale. Han blir kunstig, med spørsmål, svar, spørsmål, svar. Den gode relasjonen blir фydelagd.» (Informant E) 
Erfarne helsesjukepleiarar fortalde også at det kunne vere naudsynt å ikkje fylle ut alle spørsmåla, for heller å leggje vekt på det eleven hadde behov for å snakke om. Nokre av informantane meinte at det var lite plass til kjerneverdiar i profesjonen ved bruk av kartleggingsverktøyet:

«Det er litt krasj mellom empowerment og kartleggingsverktøyet. Det er jo ikkje noko open samtale, berre bang, bang [...].» (Informant F)

Helsesjukepleiarane problematiserte mogelegheita for at helseunders $\varnothing$ kingane opnar opp for at helsesjukepleiar kan få svar på alle spørsmåla slik dei står, utan å gi eleven noko meir. Dette kan føre til at helsesjukepleiaren kan bli meir oppteken av ansvaret for å fylle ut helseunders $\varnothing$ kingar enn å gjennomføre kjerneoppgåvene til ein helsesjukepleiar:

«Du kan liksom krysse nedover på spørsmåla. Eg synes ikkje det er ein fagleg god måte å møte elevane på. Men det hadde gått heilt fint, ingen kunne sagt at eg ikkje hadde gjort jobben min [...] sånn ut frå journalen.» (Informant A)

\section{Manglande opplæring og system for tilbakemelding}

Ingen av helsesjukepleiarane seier at dei har fått systematisert opplæring i korleis dei skal bruke kartleggingsverktøyet Helseprofil o-20: «Opplæring har mangla. Eg visste eigentleg ingenting før eg sat der den første gongen, med helseunders økinga.» (Informant G)

Alle helsesjukepleiarane i studien peikar på behovet for ei systematisk opplæring. Dei etterlyser også eit forum for regelmessig erfaringsutveksling.

\section{三 «Alle helsesjukepleiarane i studien peikar på behovet for ei systematisk opplæring.»}

Alle informantane fortalde at dei ikkje opplever at dei har høve til å gje tilbakemeldingar oppover i organisasjonen. Det er uklart kva kanalar dei skal bruke, og når dei har prøvd å gje tilbakemelding, har fleire opplevd å ikkje få svar.

Dei opplevde dermed at dei hadde lite moglegheit til å påverke bruken og utviklinga av helseunders $\varnothing$ kingane: $« \mathrm{Eg}$ trur det er slik at dei fleste av oss har gjeve opp når det gjeld å gje tilbakemelding.» (Informant A). 


\section{Diskusjon}

Denne studien viser at kartleggingsverktøyet kan utfordre brukarmedverknaden til eleven og gjere det vanskeleg for helsesjukepleiarar å leggje til rette for myndiggjering og brukarmedverknad i møte med elevar og foreldre.

Samstundes inneheld kartleggingsverktøyet mange spørsmål som kan avdekkje ulike utfordringar som er naudsynte å følgje opp.

Ifølgje Øvretveit (19) kan ein sjå på kvalitet frå ulike perspektiv. Helsesjukepleiarane påpeikte at ein kan kjenne at ein er i konflikt mellom å utføre alle punkt i helseundersøkingane, og samstundes ha eit ønske om at eleven skal kjenne seg ivareteken og høyrd. Sleveland (13) skildrar også at helsesjukepleiarar har delte meiningar om kartleggingsverkt $\varnothing \mathrm{y}$ betyr kvalitetssikring.

I vår studie kom det fram at kartleggingsverktøyet kunne avdekkje avvik hos eleven som burde fangast opp. Ifølgje Rather og medarbeidarar (20) vil elektronisk standardisert journal sikre at alle blir kartlagde på den same måten og at sentrale tema ikkje blir gløymde.

\section{$\equiv$ «Kartleggingsverktøyet kunne avdekkje avvik hos eleven som burde fangast opp.»}

Samstundes var dette noko helsesjukepleiarane hadde delte meiningar om, då dei også erfarte at det var enklare å avdekkje eventuelle utfordringar hos eleven når dei ikkje brukte kartleggingsverktøyet.

Golsäter og medarbeidarar (10) hevdar at systematiske helseog livsstilsverktøy kan vere nyttig for å gje samtalen struktur og identifisere individuelle behov, men verktøyet kan hemme dialogen om det blir brukt rigid.

\section{Fagleg skjønn må òg brukast}

Helsesjukepleiarane med mest erfaring understreka at kartleggingsverkt øyet ikkje burde brukast slik det er, men at det var naudsynt med tilpassingar frå helsesjukepleiar, med grunngjeving i eige faglege skjønn. Dette er i tråd med det Benner (21) seier om den kyndige sjukepleiaren, som blir klar over situasjonar der reglane ikkje passar og frigjer seg frå verktøyet. 
Bruk av kartleggingsverktøyet er styrande i ein slik grad at helsesjukepleiarane kan oppleve det som vanskeleg å ta utgangspunkt i behova til eleven i samtalen. Bruk av kartleggingsverktøyet kan slik føre til at helsesjukepleiarane fjernar seg frå kjerneoppgåvene sine og blir meir opptekne av å fylle ut helseunders $\varnothing$ kingane.

Eide (22) peikar på at den profesjonelle sin lojalitet kan bli retta mot å handle lydig i forhold til ytre krav og ikkje kva situasjonen krev. Når helsesjukepleiarar blir pålagde å bruke bestemte standardiserte kartleggingsverktøy i arbeidet sitt og ikkje opplever handlingsrom, så kan det skje at rekneskapsplikta får ein slik dominans at den moralske dimensjonen blir underminert (23).

Dette er kjernen i konflikten mellom den profesjonelle kompetansen til helsesjukepleiaren og ønsket om å bruke det faglege skjønnet på den eine sida, og det styrande kartleggingsverktøyet på den andre sida.

Dette samsvarar med funna til Nilsen og medarbeidarar (15), der nokre informantar følgde systemet og lét verktøyet styre, andre brukte fagkompetansen og erfaringane sine og tilpassa kartleggingsverktøyet ut frå behova til eleven.

\section{Manglande blikkontakt kan vere uheldig}

Helsesjukepleiarar i vår studie opplever at bruk av kartleggingsverkt øyet utfordrar dialogen mellom helsesjukepleiar og eleven, til dømes ved manglande blikkontakt og direkte merksemd. Rather og medarbeidarar (20), fann at ved bruk av standardisert elektronisk helsejournal kan ein lett miste viktig nonverbal informasjon og signal ein får ved å ha uforstyrra ansikt-tilansikt-kontakt.

Helsesjukepleiarane brukar ord som grilling og forhøyr når dei fortel om opplevingane sine ved å bruke kartleggingsverktøyet. Når helsesjukepleiarar brukar denne typen ord, kan det forståast slik at dei trur at kartleggingsverktøyet kan bli opplevd som negativt og kontrollerande for brukarane.

\section{$\equiv$ «Kartleggingsverktøyet utfordrar dialogen mellom helsesjukepleiar og eleven.»}


Sleveland (13) fann i unders $\varnothing$ kinga si at kartleggingsverktøya kunne føre til at borna kunne oppleve at dei kjende seg testa og kontrollerte, som vidare kunne gje dei ei kjensle av nederlag. Ifølgje Ståhl og medarbeidarar (24) er det behov for å vidareutvikle eit felles språk for å kartleggje psykososiale utfordringar og få eit meir heilskapleg syn på helsa til barn og unge i elektroniske helsejournalar.

\section{Brukarane må vere med i utviklinga}

Ingen av helsesjukepleiarane som har blitt intervjua, har fått noko systematisert opplæring i korleis dei skal bruke kartleggingsverktøyet Helseprofil o-20, og det manglar eit forum for erfaringsutveksling.

Ifølgje Rather og medarbeidarar (20) er utilfredsstillande opplæring og innføring ei generell utfordring i bruk av elektronisk helsejournal, og dette er ein barriere både i kommunikasjon og utøvinga av faget.

Det er viktig at helsearbeidarar som er tett på brukarane, deltek i kontinuerleg utvikling og forbetring av dei elektroniske helsejournalane $(14,20)$, og funna i vår studie viser at helsesjukepleiarar ønskjer mogelegheit for å gje tilbakemeldingar og på den måten å delta i kvalitetsutvikling av kartleggingsverkt фyet.

\section{Konklusjon}

Det at helsesjukepleiarane brukar eit standardisert kartleggingsverkt øy, kan både fremje og hemme kvaliteten på tenesta. Verktøyet kan gjere det vanskeleg for helsesjukepleiaren å leggje til rette for myndiggjering og brukarmedverknad, men samstundes sikrar det at sentrale tema blir tekne opp hos alle elevar.

Helsesjukepleiarane bør delta i revidering og utvikling av kartleggingsverktøya. Det er også nødvendig med opplæring og vidare diskusjon og forsking på temaet.

\section{Referanser}

1. Glavin K, Kvarme LG. Helsesøstertjenesten. Fra menighetssykepleie til folkehelsevitenskap. Oslo: Akribe Forlag; 2003.

2. DeBell D. School nurse practice: A decade of change. Community Practitioner Journal. 2006;79(10):324-27. 
3. Helsedirektoratet. Nasjonal faglig retningslinje for det helsefremmende og forebyggende arbeidet i helsestasjon, skolehelsetjeneste og helsestasjon for ungdom. Oslo:

Helsedirektoratet; 2017. Henta frå:

https://helsedirektoratet.no/retningslinjer/helsestasjons-ogskolehelsetjenesten (lasta ned 22.02.2018).

4. Forskrift 19. oktober $2018 \mathrm{nr} .1584$ om kommunens helsefremmende og forebyggende arbeid i helsestasjons- og skolehelsetjenesten. Henta frå: https://lovdata.no/dokument/SF/forskrift/2018-10-191584 (lasta ned: 22.06.2019).

5. Meld. St. 19 (2014-2015). Om Folkehelsemeldingen mestring og muligheter. Oslo: Helse- og omsorgsdepartementet; 2018. Henta frå: https://www.regjeringen.no/no/dokumenter/meld.-st.-19-20142015/id2402807/?ch=1 (lasta ned 02.12.2020).

6. Klepp KI, Stigen OT, Aarø LE. Folkehelse og folkehelsearbeid blant barn og unge i Norge. I: Klepp KI, Aarø LE, red. Ungdom, livsstil og helsefremmende arbeid. 4. utg. Oslo: Gyldendal Akademisk; 2017. s. 17-36.

7. $\quad$ Forskrift 1. mars 2019 nr. 168 om pasientjournal (pasientjournalforskriften). Henta frå: https://lovdata.no/dokument/SF/forskrift/2019-03-01-168? $\mathrm{q}=$ pasientjournal (lasta ned 10.12.2019).

8. Naidoo J, Wills J. Foundations for health promotion. 4. utg. Edinburgh: Elsevier; 2016.

9. Bentzen A. Fikk pris for unikt helseprosjekt. Bergen: Bergen kommune; 2018. Henta frå: https:/www.bergen.kommune.no//hvaskjer/tema/kunnskapsk ommunen/hva-skjer/fikk-pris-for-unikt-helseprosjekt (lasta ned 10.12.2019).

10. Golsäter M, Lingfors H, Sidenvall B, Enskär K. Health dialogues between pupils and school nurses: A description of the verbal interaction. Patient Educ Couns. 2012;89(2):260-6.

11. Høifødt VH . Skolehelsetjenesten i et brukerperspektiv. En kvalitativ studie av ungdoms erfaringer og behov i møte med skolehelsetjenesten. (Masteroppgåve.) Trondheim: Norges teknisk-naturvitenskapelige universitet, Institutt for pedagogikk og livslang læring; 2015. 
12. Borup I. The school health nurse's assessment of a successful health dialogue. Health and Social Care in the Community. 2002;10(1):10-9.

13. Sleveland B. Helses $\varnothing$ sters erfaringer ved bruk av kartleggingsverkt $\varnothing y$ på helsestasjonen for barn o-5 år (Masteroppgåve.) Troms $\varnothing$ : Universitetet i Troms $\varnothing$, Det helsevitenskapelige fakultet; 2015.

14. Gephart S, Carrington JM, Finley B. A systematic review of nurses' experiences with unintended consequences when using the electronic health record. Nurs Adm Q. 2015;39(4):345-56.

15. Nilsen I, Litland AS, Hjälmhult E. Helsesøstres utfordringer ved bruk av kartleggingsverkt $\varnothing \mathrm{y} i$ skolehelsetjenesten. Sykepleien Forskning. 2014;9(4):358. DOI: $\underline{10.4220 / \text { sykepleienf.2014.0171 }}$

16. Øren TL. Kartleggingsverktøy i skulehelsetenesta helses $\varnothing$ ster sine erfaringar med bruk av målretta helseundersøkingar. (Masteroppgåve.) Bergen: Høgskulen på Vestlandet, Fakultet for økonomi og samfunnsvitskap; 2018.

17. Thagaard T. Systematikk og innlevelse. En innføring i kvalitativ metode. 4. utg. Bergen: Fagbokforlaget; 2013.

18. Malterud K. Kvalitative forskningsmetoder for medisin og helsefag. 4. utg. Oslo: Universitetsforlaget; 2017.

19. Bukve O, Kvåle G. Samhandling og kvalitet i helseorganisasjonar. Oslo: Universitetsforlaget; 2014.

20. Rather C, Porter TH, Mittler JN, Fleig-Palmer M. Seven years after meaningful use: physicians' and nurses' experiences with electronic health records. Health Care Manage Rev. 2019;44(1):30-40.

21. Benner P. Fra novise til ekspert - dyktighet og styrke i klinisk sykepleiepraksis. København: Tano Forlag; 1984/1995. Henta frå: https://www.nb.no/nbsok/nb/d57b7ded37e0140923dod7acecb b734e?lang=no\#o (lasta ned 02.02.2018).

22. Eide SB. Individuelt ansvar og sløvhet i profesjonsutøvelse. Etikk i praksis - Nordic Journal of Applied Ethics. 2012;6(2):64-79. 
23. Solbrekke T, Østrem S. Profesjonsut Øvelse mellom profesjonelt ansvar og regnskapsplikt. Nordic Studies in Education. 2011;31:194-209.

24. Ståhl Y, Granlund M, Gäre-Andersson B, Enskär K. Review article: Mapping of childrens health and development data on population level using the classification system ICFCY. Scandinavian Journal of Public Health. 2011;39:51-7. 